\title{
ANALISIS METODE VACUUM PRELOADING UNTUK MEMPERCEPAT KONSOLIDASI PADA TANAH LEMPUNG LUNAK JENUH AIR
}

\author{
Hadrian Edwin ${ }^{1}$, Andryan Suhendra ${ }^{2}$ \\ ${ }^{1}$ Program Studi Sarjana Teknik Sipil, Universitas Tarumanagara, Jl. Letjen S. Parman No.1 Jakarta \\ Email: Hadrian.edwin1@gmail.com \\ ${ }^{2}$ Civil Engineering Department, Faculty of Engineering, Binus University \\ Jl. K.H. Syahdan No. 9, Palmerah, Jakarta Barat 11480 \\ Email: andryan@geosinindo.co.id ; asuhendra@binus.ac.id;
}

\begin{abstract}
ABSTRAK
Konsolidasi adalah proses pemampatan tanah akibat adanya beban tetap dalam waktu tertentu yang menyebabkan tanah yang berada di bawah beban tersebut akan mengalami penurunan yang merata maupun tak merata yang akan mengakibatkan ketidakstabilan struktur yang akan berbahaya untuk struktur yang berada diatas tanah tersebut Tanah lempung lunak jenuh air menimbulkan banyak masalah dalam dunia konstruksi disebabkan oleh waktu konsolidasi yang lama dan kuat geser yang sangat kecil yang dapat menimbulkan kerusakan pada bangunan yang berada diatasnya, maka di perlukan perbaikan tanah untuk mengatasi masalah yang ditimbulkan tanah lempung lunak jenuh air. Vacuum preloading adalah sebuah meode alternatif untuk perbaikan tanah lempung lunak jenuh air yang memiliki kadar air yang tinggi dan memiliki waktu konsolidasi yang sangat lama dengan cara percepatan proses konsolidasi.. Perhitungan teoritis untuk memperkirakan besarnya penurunan konsolidasi menggunakan metode kosnolidasi satu dimensi dari Terzaghi didapatkan hasil penurunan sebesar 40,86 cm. Sedangkan untuk memperkirakan besar penurunan konsolidasi yang terjadi di lapangan menggunakan metode Asaoka yang menunjukan penurunan sebesar 41,1 dengan derajat konsolidasi sebesar 99,72 \%. Perbandingan hasil perhitungan teoritis dengan hasil monitoring akan menunjukan keberhasilan metode vacuum preloading sebagai metode alternatif percepatan konsolidasi pada tanah lempung.
\end{abstract}

Kata kunci: Percepatan Konsolidasi, Tanah lempung lunak jenuh air, Vacuum preloading.

\section{PENDAHULUAN}

Persebaran tanah lempung lunak di Indonesia cukup merata, melihat luasnya daerah tanah lempung yang dimiliki hampir di setiap pulau. Sebagian besar tanah yang berada pada daerah timur Pulau Sumatera adalah tanah lempung lunak, dimana tanah tersebut memiliki kandungan air yang sangat tinggi dan waktu konsolidasi yang sangat panjang bila di beri beban di atas tanah tersebut. Tanah lempung lunak sering kali menimbulkan permasalahan pada struktur diatasnya yang disebabkan oleh masalah daya dukung yang lemah dan masalah waktu konsolidasi yang lama dari tanah ini. Oleh karena itu diperlukan adanya usaha perbaikan tanah untuk memperbaiki tanah lempung lunak ini. Metode Preloading atau yang biasa di sebut prabeban merupakan sebuah metode untuk memperbaiki masaah yang ditimbulkan taah lempung lunak namun pada proses pelaksanaanya metode ini sering mengalami banyak permasalahan diantaranya adalah kelongsoroan tanah timbunan selain itu metode ini juga memakan ongkos yang sangat besar diarenakan perpindahan tanah timbunan yang harus di lakukan. Vacuum preloading merupakan salah satu alternatif untuk emperbaiki taah lempung lunak jenuh air, pertama kali di perkenalkan oleh Kjellman tahun 1952 (Suhendra, et al., 2011) dimana pompa vakum akan menghisap air dan udara di dalam tanah yang sudah di beri lembaran kedap udara diatasnya, dengan begitu penurunan konsolidasi pada tanah akan terjadi dengan waktu yang lebih cepat dibanding metode terdahulunya.

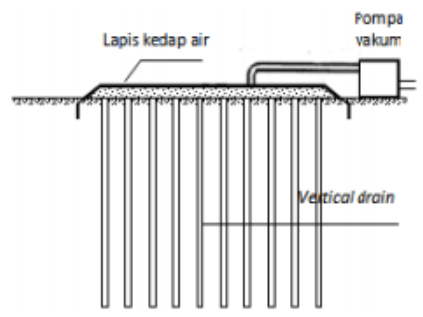




\section{METODOLOGI PENELITIAN}

\section{Data monitoring}

Pengujian hand boring dilakukan di lapangan guna mendapatkan nilai SPT yang dinyatakan dalam jumlah N pukulan dan kondisi tanah lapangan yang akan diberlakukan metode vacuum preloading. Uji laboratorium juga di lakukan guna mendapatkan parameter-parameter yang di perukan untuk perhitungan penurunan konsolidasi dan kenaikan kuat geser yang terjadi. Pengujian sondir dilakukan di lapangan guna mendapatkan nilai qc yang nantinya akan dikoreasikan untuk mendapat nilai kuat geser pada tanah

\section{Tanah lempung}

Tanah lempung lunak merupakan tanah kohesif yang memiliki partikel butran-butiran yang sangat kecil berukuran lebih kecil dari 2 mikron. Tanah lempung memiliki sifat geser yang kecil, permeabilitas yang kecil, waktu konsolidasi yang sangat lama, dan daya dukung tanah yang kecil sehingga sering menimbulkan permasalahan di dunia konstruksi baik dari sisi biaya maupun mengancam ketahanan struktur yang berada di atas tanah lempung ini. Maka di perlukan perbaikn tanah guna mengatasi masalah-masalah yang ditimbulkan oleh tanah lepung lunak.

\section{Penurunan tanah}

Penuruan pada tanah atau yang biasa disebut dengan konsolidasi pada tanah adalah suatu permasalahan yag paling sering dijumpai pada tanah. Penurunan konsolidasi adalah penurunan pada tanah kohesif yang disebabkan oleh terdisipasinya tegangan air berlebih di dalam tanah, dan meghasilkan perubahan volume tanah yang megalami penurunan. Untuk menguji penurunan pada tanah biasanya dilakukan di dalam laboratorium dengan menggunakan alat yang bernama oedometer.

\section{HASIL DAN PEMBAHASAN}

\section{Perhitungan analitis penurunan konsolidasi}

Pada proyek sebesar $4000 \mathrm{~m}^{2}$ dengan panjang 100 meter dan lebar 40 meter diberlakukan metode vacuum preloading dengan besar pompa vakum sebesar $81 \mathrm{kPa}$ dan tanah timbunan setinggi 1 meter dengan berat jenis tanah timbunan sebesar $18 \mathrm{kN} / \mathrm{m}^{3}$. Jarak antar PVD adalah 1 meter dengan tebal PVD sebesar $3 \mathrm{~mm}$ dan lebar 100 $\mathrm{mm}$.

Tabel 1. Komponen perhitungan konsolidasi.

\begin{tabular}{cccccccc}
\hline $\begin{array}{c}\text { Kedalaman } \\
(\mathrm{m})\end{array}$ & $\mathrm{z}(\mathrm{m})$ & $\begin{array}{c}\gamma_{\mathrm{sat}} \\
\left(\mathrm{kN} / \mathrm{m}^{3}\right)\end{array}$ & $\begin{array}{c}\text { Po' } \\
\left(\mathrm{kN} / \mathrm{m}^{2}\right)\end{array}$ & Cc & eo & Cr & $\begin{array}{c}\text { Pc' } \\
\left(\mathrm{kN} / \mathrm{m}^{2}\right)\end{array}$ \\
\hline $0-3$ & 3 & 16,62 & 9,93 & 0,427 & 1,32558 & 0,0515 & 83 \\
\hline $3-8$ & 5 & 15,88 & 34,56 & 0,434 & 1,43902 & 0,0767 & 167 \\
\hline $8-13$ & 5 & 17,39 & 67,73 & 0,344 & 1,04081 & 0,0643 & 125 \\
\hline $13-15,5$ & 2,5 & 17,68 & 95,81 & 0,249 & 0,92307 & 0,058 & 149 \\
\hline
\end{tabular}

Tabel 2. Penurunan konsolidasi

\begin{tabular}{cccccc}
\hline Lapisan & Kedalaman $(\mathrm{m})$ & $\mathrm{z}(\mathrm{m})$ & $\mathrm{Po}^{\prime}\left(\mathrm{kN} / \mathrm{m}^{2}\right)$ & $\mathrm{Pc}^{\prime}\left(\mathrm{kN} / \mathrm{m}^{2}\right)$ & $\mathrm{Sc}(\mathrm{m})$ \\
\hline 1 & $0-3$ & 3 & 9,93 & 83 & 0,124 \\
\hline 2 & $3-8$ & 5 & 34,56 & 167 & 0,091 \\
\hline 3 & $8-13$ & 5 & 67,73 & 125 & 0,145 \\
\hline 4 & $13-15,5$ & 2,5 & 95,81 & 149 & 0,047 \\
\hline & & & & Total & 0,408 \\
\cline { 3 - 6 }
\end{tabular}


Pada Penelitian kali ini semua lapisan tanah mengalami konsolidasi berlebih (overlyconsolidated) dikarenakan nilai OCR $\neq 1$. Besar penurunan konsolidasi akibat beban vakum dan beban timbunan adalah sebesar 0,408 meter atau sama dengan $40,8 \mathrm{~cm}$.

\section{Perhitungan analitis waktu konsolidasi}

Waktu penurunan Konsolidasi akibat proses vakum dapat di lihat pada tabel 3.

Tabel 3. Waktu penurunan konsolidasi

\begin{tabular}{ccc}
\hline No & $\mathrm{U}(\%)$ & Waktu (hari) \\
\hline 1 & $25 \%$ & 5,492 \\
\hline 2 & $50 \%$ & 13,233 \\
\hline 3 & $75 \%$ & 26,466 \\
\hline 4 & $99,72 \%$ & 131,870 \\
\hline
\end{tabular}

Waktu yang dibutuhkan untuk mencapai derajat konsolidasi sebesar 99,725\% adalah selama 131,87 hari.

\section{Perhitungan analitis kenaikan kuat geser}

Hasil peningkatan kuat geser yang terjadi setelah diberlakukannya metode vacuum preloading dapat dilihat pada tabel 4 .

Tabel 4. Peningkatan kuat geser setelah vakum

\begin{tabular}{cccc}
\hline Kedalaman $(\mathrm{m})$ & $\mathrm{c}^{\prime}\left(\mathrm{kN} / \mathrm{m}^{2}\right)$ & $\mathrm{c}\left(\mathrm{kN} / \mathrm{m}^{2}\right)$ & Peningkatan \\
\hline 2 & 30 & 51,505 & $71,68 \%$ \\
\hline 4 & 20 & 41,501 & $107,51 \%$ \\
\hline 6 & 35 & 56,489 & $61,40 \%$ \\
\hline 8 & 70 & 91,468 & $30,67 \%$ \\
\hline 10 & 15 & 36,435 & $142,90 \%$ \\
\hline 12 & 14 & 35,386 & $152,76 \%$ \\
\hline 14 & 20 & 41,321 & $106,61 \%$ \\
\hline
\end{tabular}

Terjadi peningkatan kuat geser setalah dilakukan perbaikan menggunakan metode vacuum preloading dengan ratarata kenaikan sebesar 96,22 \%.

\section{Hasil monitoring penurunan konsolidasi}

Dari data monitoring dilakukan analisis untuk memperkirakan penurunan konsolidasi yang terjadi menggunakan metode Asaoka (Pd T-06-2004-B) yang akan di tampilkan pada gambar 1. 


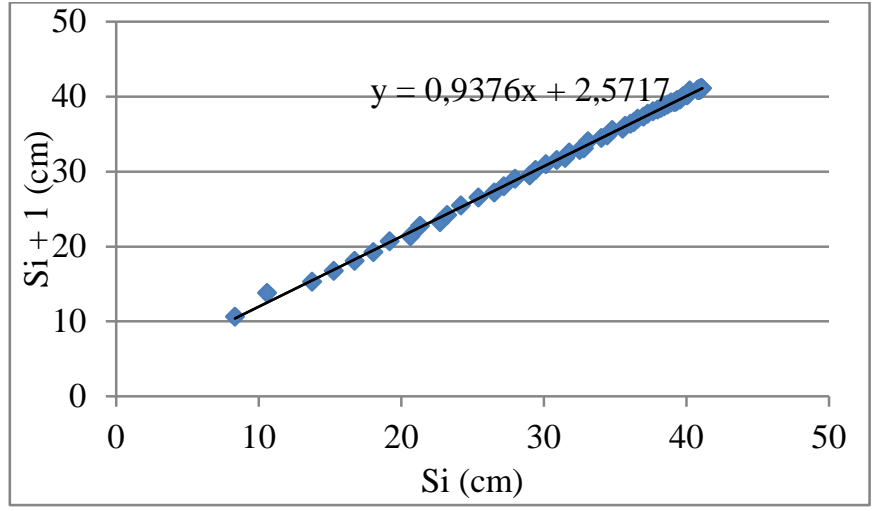

Gambar 2. Perkiraan penurunan konsolidasi menggunakan metode Asaoka

Dari grafik Asaoka di temukan persamaan garis linear $\mathrm{y}=0,9376 \mathrm{x}+2,5717$. Penurunan maksimum menurut metode Asaoka adalah sebesar 41,213 cm pada derajat konsolidasi $100 \%$ sehingga penurunan sebesar 41,1 cm dari hasil monitoring, derajat konsolidasi yang dicapai adalah 99,725 \%.

\section{Hasil Monitoring waktu konsolidasi}

Hasil monitoring yang dilakukan di lapangan dapat di lihat pada gambar 3.

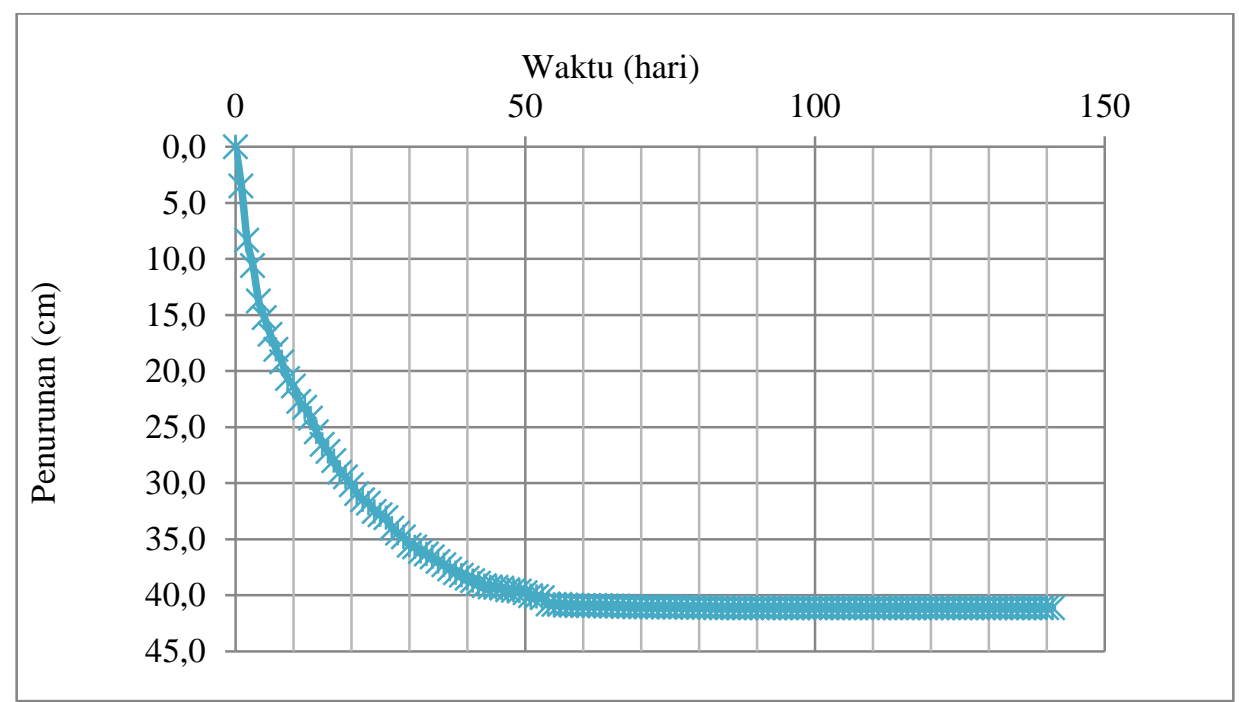

Gambar 3. Grafik penurunan - waktu

Dari grafik diatas dapat dilihat penurunan maksimum yang terjadi sebesar 41,1 cm dan membutuhkan waktu sekitar 83 hari untuk mencapai derajat konsolidasi 99,725\%.

\section{Perbandingan hasil}

Berikut adalah hasil perbandingan penurunan konsolidasi dan waktu yang terjadi di lapangan dengan perhitungan analitis. 
Tabel 5. Perbandingan hasil analitis dengan monitoring

\begin{tabular}{cccc}
\hline Hari ke- & Teoritis & Monitoring & Selisih \\
\hline 0 & $0,00 \mathrm{~cm}$ & $0,00 \mathrm{~cm}$ & $0,00 \%$ \\
\hline 3 & $5,96 \mathrm{~cm}$ & $10,00 \mathrm{~cm}$ & $43,78 \%$ \\
\hline 5 & $9,44 \mathrm{~cm}$ & $15,27 \mathrm{~cm}$ & $38,17 \%$ \\
\hline 10 & $16,71 \mathrm{~cm}$ & $20,66 \mathrm{~cm}$ & $19,13 \%$ \\
\hline 20 & $26,60 \mathrm{~cm}$ & $30,17 \mathrm{~cm}$ & $11,23 \%$ \\
\hline 30 & $32,46 \mathrm{~cm}$ & $35,53 \mathrm{~cm}$ & $8,62 \%$ \\
\hline 40 & $35,93 \mathrm{~cm}$ & $38,47 \mathrm{~cm}$ & $6,59 \%$ \\
\hline 50 & $37,99 \mathrm{~cm}$ & $39,77 \mathrm{~cm}$ & $4,47 \%$ \\
\hline 60 & $39,21 \mathrm{~cm}$ & $40,93 \mathrm{~cm}$ & $4,20 \%$ \\
\hline 70 & $39,93 \mathrm{~cm}$ & $41,03 \mathrm{~cm}$ & $2,68 \%$ \\
\hline 80 & $40,36 \mathrm{~cm}$ & $41,07 \mathrm{~cm}$ & $1,73 \%$ \\
\hline 90 & $40,61 \mathrm{~cm}$ & $41,10 \mathrm{~cm}$ & $1,19 \%$ \\
\hline 100 & $40,76 \mathrm{~cm}$ & $41,10 \mathrm{~cm}$ & $0,28 \%$ \\
\hline 110 & $40,85 \mathrm{~cm}$ & $41,10 \mathrm{~cm}$ & $0,61 \%$ \\
\hline 120 & $40,86 \mathrm{~cm}$ & $41,10 \mathrm{~cm}$ & $0,48 \%$ \\
\hline
\end{tabular}

Terjadi perbedaan antara perhitungan teoritis dengan hasil monitoring yang disebabkan oleh penentuan parameterparameter tanah yang kurang tepat pada lapisan tanah. Untuk mendapatkan hasil yang lebih baik sebaiknya menggunakan data lab yang lebih lengkap. Perhitungan teoritis juga tidak memperhitungkan beban horizontal, hanya beban vertikal yang diperhitungkan sehingga menyebabkan perbedaan hasil.

\section{Perbandingan kenaikan kuat geser}

Berikut adalah hasil perbandingan kenaikan kuat geser berdasarkan hasil analitis dengan hasil monitoring.

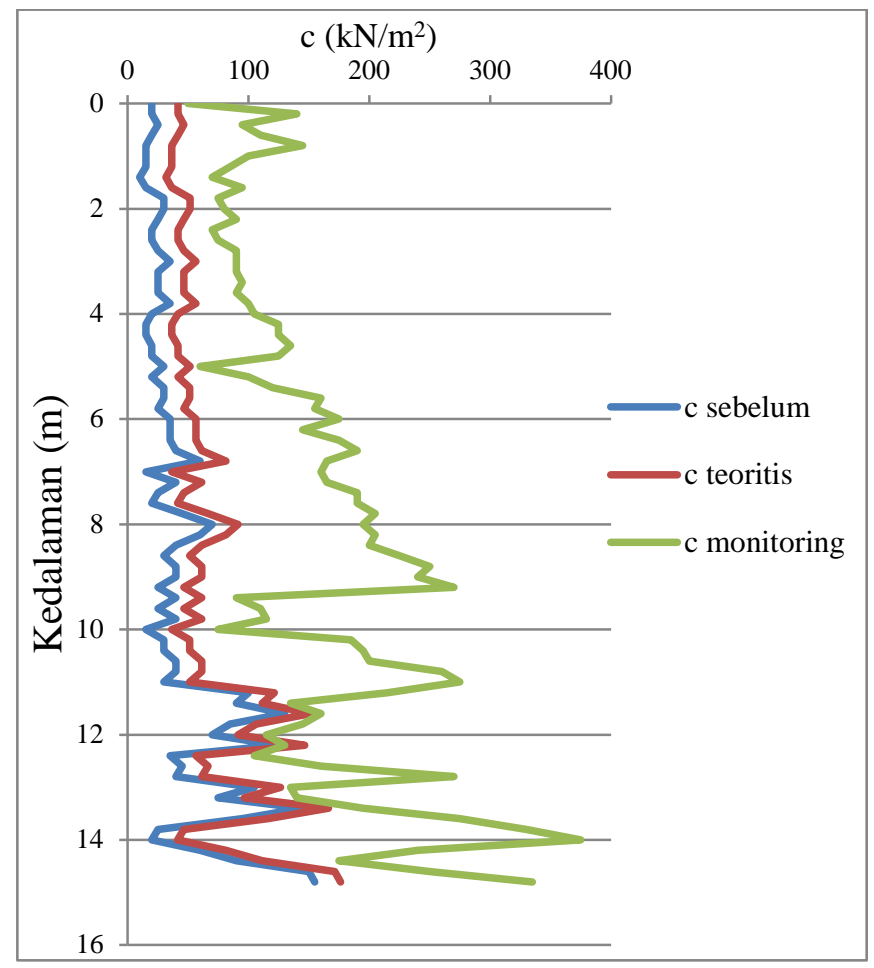

Gambar 4. Perbandingan Kenaikan kuat geser 
Dari data diatas dapat dilihat terdapat kenaikan kuat geser yang cukup besar terjadi pada lapangan. Hal ini disebabkan oleh terjadinya penurunan konsolidasi. Terjadi perbedaan antara perhitungan teoritis dengan hasil monitoring yang disebabkan oleh faktor pengali pada saat mencari kenaikan kuat geser diambil 0,22 (Mesri, 1999) sedangkan faktor pengali untuk mencari kenaikan kuat geser berdasarkan hasil monitoring lapangan berada diantara $0,3-3,6$.

\section{PERSAMAAN}

\section{Penurunan dan waktu konsolidasi}

Besar penurunan konsolidasi yang terjadi dapat di peroleh dengan persamaan:

$$
S c=C r \frac{H}{1+e o} \log \frac{P o^{\prime}+\Delta p}{P o^{\prime}}
$$

dan persamaan:

$$
S c=C r \frac{H}{1+e o} \log \frac{P c^{\prime}}{P o^{\prime}}+C c \frac{H}{1+e o} \log \frac{P o^{\prime}+\Delta p}{P o^{\prime}}
$$

dengan $\mathrm{Sc}=$ besar penurunan konsolidasi, $\mathrm{H}=$ kedalaman, $\mathrm{e}_{0}=$ angka pori awal, $\mathrm{Cc}=$ nilai pemampatan, Po'= tekanan overburden efektif mula-mula, $\mathrm{Pc}^{\prime}=$ tekanan prakonsolidasi, $\mathrm{Cr}=$ indeks pemampatan $\mathrm{kembali}, \Delta \mathrm{p}=$ kenaikan tegangan tanah.

Sedangkan untuk mendapatkan waktu pada derajat konsolidasi yang diinginkan menggunakan persamaan :

$$
t=\left(\frac{D^{2}}{8 \times C h}\right) \times 2 F(n) \times \ln \left(\frac{1}{1-U h}\right)
$$

dengan $\mathrm{t}=$ waktu yang diperlukan untuk mencapai Uh, $\mathrm{D}=$ diameter pengaruh lingkaran, Ch = koefisien aliran horizontal, $\mathrm{F}(\mathrm{n})$ = faktor hambatan yang disebabkan oleh jarak antar PVD, Uh = derajat konsolidasi.

\section{Peningkatan kuat geser}

Peningkatan kuat geser pada tanah yang mengalami konsolidasi dengan PVD menggunakan persamaan:

$$
\left(\frac{\Delta C u}{\sigma_{P}{ }^{\prime}}\right)=0,22
$$

dan persamaan :

$$
C u=\Delta C u+C u^{\prime}
$$

dengan $\sigma_{\mathrm{P}}{ }^{\prime}=$ tegangan overburden efektif setelah pemampatan, $\mathrm{Cu}$ ' $=$ kuat geser mula-mula, $\Delta \mathrm{Cu}=$ peningkatan kuat geser akibat pemampatan, $\mathrm{Cu}=$ kuat geser setelah pemampatan.

\section{KESIMPULAN}

Dari hasil penelitian di atas dapat diambil beberapa kesimpulan, berikut adalah beberapa kesimpulan yang dapat diambil: Metode Vacuum Preloading terbukti mampu mempercepat waktu penurunan tanah lempung lunak jenuh air yang memiliki waktu konsolidasi sangat lama menjadi hanya sekitar 90 hari. Metode vacuum preloading lebih mudah dilakukan dibanding metode sebelumnya yaitu metode preloading yang menaruh timbunan tanah diatasnya, karena dengan tekanan vakum yang dapat mencapai tegangan $80 \mathrm{kPa}$ yang membuat tegangan efektif pada tanah dapat naik setara dengan jika diberi tanah timbunan setinggi 4,5 meter dengan asumsi dengan berat volume tanah sebesar $18 \mathrm{kN} / \mathrm{m}^{3}$. Terjadi peningkatan kuat geser yang cukup signifikan setelah terjadinya pemampatan tanah menggunakan metode vacuum preloading.

\section{DAFTAR PUSTAKA}

Mesri, G., and Ali, S. Géotechnique. Undrained Shear Strength of a glacial clay overconsolidated by desiccation, 1999. ICE Publishing, 181-198 
Pd T-06-2004-B . Pedoman Perancangan Konstruksi Timbunan Jalan di atas Gambut dengan Metode Prapembebanan.

Suhendra A., Irsyam M. Studi aplikasi vacuum preloading sebagai metode alternatif percepatan proses konsolidasi pada tanah lempung lunak jenuh air. Jurnal ComTech. Vol. 2. No. 2 (Desember 2011): 1055-1065. 
Analisis Metode Vacuum Preloading Untuk Mempercepat

Hadrian Edwin, et al.

Konsolidasi pada Tanah Lempung Lunak Jenuh Air 